\title{
A case of hybrid medical management of advanced cornual ectopic pregnancy
}

\author{
Shilpa Bajpai*, Prasad Lele
}

Department of Obstetrics and Gynecology, Institute of Naval Medicine, INHS Asvini, Mumbai, Maharashtra, India

Received: 27 September 2020

Revised: 07 November 2020

Accepted: 10 November 2020

\author{
*Correspondence: \\ Dr. Shilpa Bajpai, \\ E-mail: drshilpa_afmc85@yahoo.co.in
}

Copyright: (c) the author(s), publisher and licensee Medip Academy. This is an open-access article distributed under the terms of the Creative Commons Attribution Non-Commercial License, which permits unrestricted non-commercial use, distribution, and reproduction in any medium, provided the original work is properly cited.

\begin{abstract}
Cornual ectopic pregnancy is perilous and treacherous entity which accounts for $2-4 \%$ of all ectopic pregnancies and has a maternal mortality of $2-2.5 \%$. There is always a dilemma in diagnosis due to the area being in close proximity to the endometrial cavity. The precise localisation is difficult till the gestation is advanced, which poses problems in its subsequent management. Surgical approach in this highly vascular area leads to excessive bleeding is a daunting nightmare for a surgeon and also imposes a great threat to the future fertility of the patient. Here we present a case of 26 year old spontaneously conceived primigravida who presented for booking visit at 10 week period of gestation. On transvaginal sonography, there was a suspicion of right cornual ectopic pregnancy which was later confirmed on magnetic resonance imaging (MRI). Despite due to advanced viable gestation, with an evident cardiac activity and very high serum $\beta$-human chorionic gonadotropin $(\beta \mathrm{hCG})$ (more than 1 lakh $\mathrm{mIU} / \mathrm{ml}$ ), we tried a pioneering technique of conservative hybrid approach with intracavitary instillation and systemic antimetabolite drug methotrexate, in view to safeguard her future fertility by diminishing the likelihood of hysterectomy. While on the treatment, patient developed hyper reaction to methotrexate, which was managed with a multidisciplinary approach. She responded very well to the therapy with complete resolution of the cornual ectopic pregnancy.
\end{abstract}

Keywords: Cornual ectopic pregnancy, $\beta \mathrm{hCG}$, Methotrexate, Hybrid approach

\section{INTRODUCTION}

Pregnancy implantation in the intrauterine portion of fallopian tube is known as cornual ectopic or interstitial ectopic pregnancy. ${ }^{1}$ These cases may rupture with massive haemorrhage and present as medical emergency necessitating immediate surgical intervention. However, few patients may be asymptomatic and managed conservatively.

Here authors present a case of 26 year old spontaneously conceived primigravida who presented at 10 weeks period of gestation for routine antenatal check-up and was incidentally detected to have the pregnancy located in the right cornu. Keeping the prospects of her future fertility we tried a hybrid approach with methotrexate. The elaborated case report along with its review of literature is presented in subsequent paragraphs below.

\section{CASE REPORT}

26 years old primigravida, spontaneously conceived, presented for routine antenatal checkup, with history of amenorrhea of 2 and a half months. There was no history of pain abdomen, bleeding per vaginum, any use of contraception or tubal surgery. No history of assisted reproductive technology (ART) procedures or no history of tuberculosis (TB) in past was elicited.

On examination at our centre, she had body mass index (BMI) of $19.5 \mathrm{~kg} / \mathrm{m}^{2}$. Respiratory system, central nervous system and cardiovascular system examination were 
essentially normal. Abdomen was soft and non-tender. On transvaginal sonography, a viable pregnancy of 10 weeks 6 days with fetal cardiac activity was seen near right cornu, as evident in Figure 1.

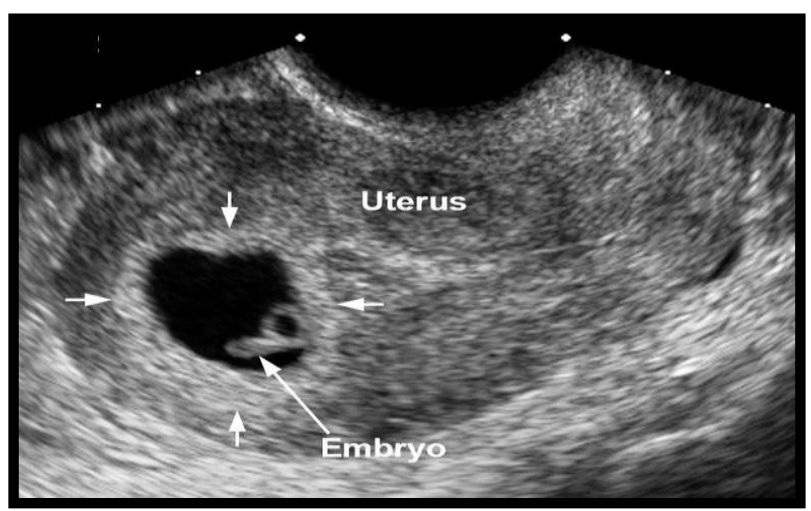

Figure 1: On transvaginal sonography, a viable pregnancy 10wks 6days with fetal cardiac activity was seen near right cornu.

In the Figure 2, ultrasonography revealed empty uterine cavity with an eccentrically located pregnancy in right cornu.

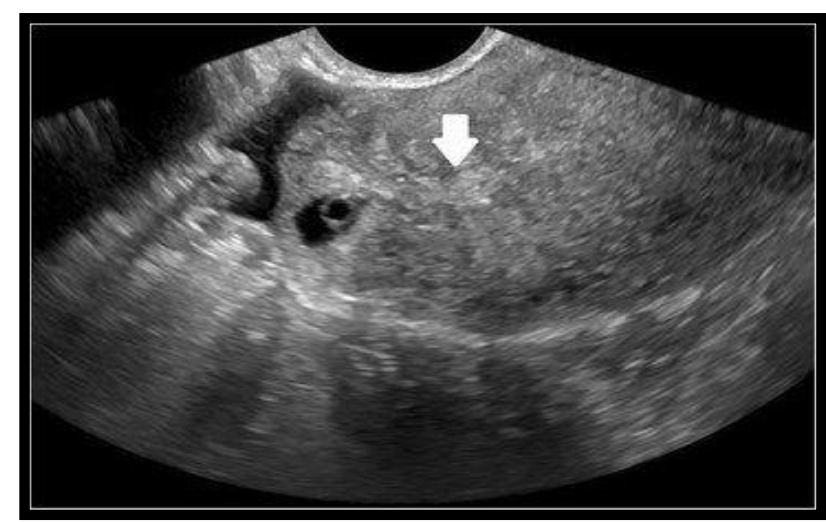

Figure 2: Ultrasonography revealed empty uterine cavity with an eccentrically located pregnancy in right cornu.

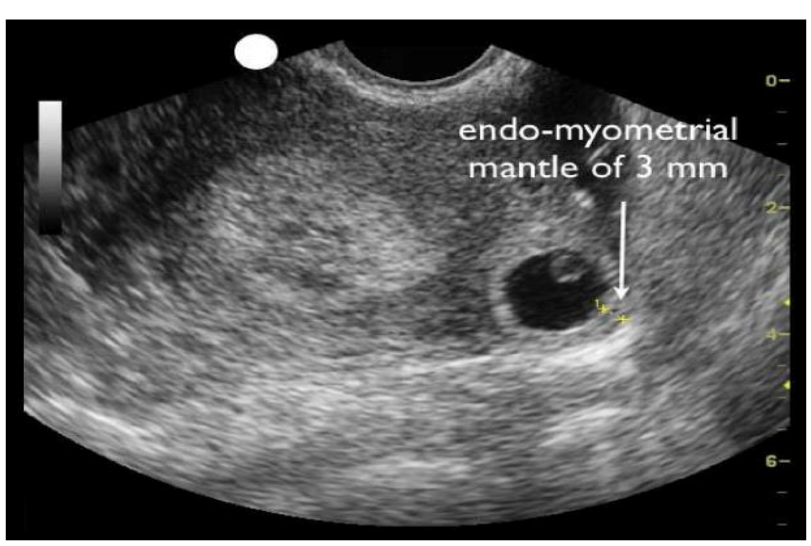

Figure 3: A thin myometrial layer ( $<5 \mathrm{~mm})$ around the gestation sac.
For further confirmation, magnetic resonance imaging (MRI) was done which confirmed an eccentrically located heterogeneous mass, suggestive of gestational sac, along with abnormal thinning of myometrial mantle and a prominent interstitial line sign seen clearly in Figure 4 below.

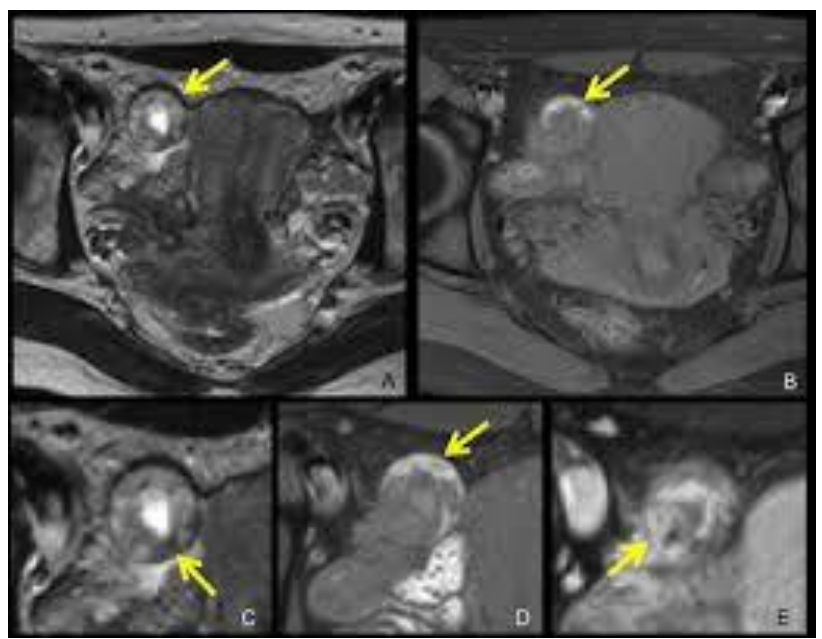

Figure 4: MRI showing an eccentrically located heterogenous mass, suggestive of gestational sac, alongwith abnormal thinning of myometrial mantle and a prominent interstitial line sign seen.

The baseline serum $\beta \mathrm{hCG}$ was $1,41,480 \mathrm{mIU} / \mathrm{ml}$. Her initial haematological and biochemical parameters were within normal limits. Despite her advanced viable gestation and high serum $\beta$ hCG, decision was taken for hybrid management with intracavitary and systemic methotrexate therapy, keeping in mind about her future fertility preservation and after elaborated counseling and obtaining due consent from the patient. Further progress of the treatment and follow up was done with serial serum $\beta$ hCG monitoring and transvaginal sonography.

On initial day of therapy, USG guided embryo reduction was done by instillation of $0.1 \mathrm{ml}$ intracardiac injection of potassium chloride. The cessation of fetal cardiac activity was confirmed by ultrasound. In view of the fact that the levels of $\beta \mathrm{hCG}$ were lofty, injection methotrexate $50 \mathrm{mg}$ was also injected into the gestational sac in the same sitting.

Owing to the increased levels of $\beta \mathrm{hCG}$, accordance was taken to compliment the systemic methotrexate alternating with leucovorin as per multidose regime for management of ectopic pregnancy. Following the initial two doses of intravenous methotrexate (50 mg each) on day 1 and day 3 , patient developed signs of hyper reaction to methotrexate in form of ulcerative stomatitis and macular rash. Decision to stop further doses of methotrexate was taken. The serum methotrexate levels after 72 hours of the last dose were $1.5 \mu \mathrm{mol} / \mathrm{l}$ which was marginally raised from the normal value. Subsequently, patient developed pancytopenia and elevated levels of transaminases. Strict 
barrier nursing protocol was initiated. The toxicity was managed with intravenous leucovorin under the antibiotic cover. Pancytopenia was corrected with granulocyte colony-stimulating factor (G-CSF).

By day 7 , the serum $\beta$ hCG was $83,337 \mathrm{mIU} / \mathrm{ml}$ and transvaginal sonography showed a reducing sac and patient improved symptomatically. Serum methotrexate levels done on day 9 were $0.215 \mu \mathrm{mol} / \mathrm{l}$. The serum $\beta \mathrm{hCG}$ on day 9 was $31,446 \mathrm{mIU} / \mathrm{ml}$ and subsequently on day 13 , it was $8190 \mathrm{mIU} / \mathrm{ml}$.

On day 17, patient was asymptomatic with all haematological and parameters within normal limits. The serum $\beta \mathrm{hCG}$ was $1732 \mathrm{mIU} / \mathrm{ml}$ and TVS suggested complete resorption of the cornual ectopic pregnancy. The patient was discharged with weekly follow up of serum $\beta$ hCG till it came below the reference value.

\section{DISCUSSION}

Cornual ectopic pregnancies are rare but pose difficulty in diagnosis till the gestation is advanced. Transvaginal sonography is the preferred modality in diagnosis. The diagnosis is difficult till the gestation is advanced as the area is very close to endometrial cavity. Hence MRI may be needed for confirmation.

With advent of assisted reproductive techniques, incidence of ectopic pregnancy is on the rise. Despite the widespread use of transvaginal sonography and serum $\beta \mathrm{hCG}$ assays, their diagnosis gets delayed, since this part of the tube has good muscular and vascular support which results in greater distensibility and thus causes less pain. ${ }^{2}$ Due to abundant blood supply in cornual region from both uterine and ovarian vessels, rupture occurring after 12 weeks of gestation often leads to severe haemorrhage and eventually maternal death. ${ }^{11}$

Interstitial pregnancy is usually diagnosed by ultrasonography and many cases during laparotomy after rupture of ectopic pregnancy. The sonographic criteria for diagnosis include empty uterine cavity, chorionic sac separated $<1 \mathrm{~cm}$ from most lateral edge of uterine cavity, and thin myometrial layer $(<5 \mathrm{~mm})$ surrounding the sac. ${ }^{1}$ Sonographic findings in two dimensions can be further confirmed using three-dimensional ultrasound, where available, to avoid misdiagnosis with early intrauterine or angular pregnancy. ${ }^{12}$

Ackerman et al described the interstitial line sign, which refers to the visualization of an echogenic line that runs from the endometrial cavity to the interstitial region, abutting the interstitial mass or gestational sac. ${ }^{13}$

Conventionally, methotrexate is administered if the patient meets following criteria: when patient is haemodynamically stable, no embryonic cardiac activity, gestational sac diameter $<3.5 \mathrm{~cm}^{2}$, $\beta$ hCG levels $<5000$ $\mathrm{IU} / \mathrm{ml}$, and in a tertiary care centre where emergency laparotomy can be undertaken. ${ }^{4}$ An randomized controlled trials (RCT) comparing methotrexate with laparoscopic salpingostomy surgery for tubal ectopics showed that methotrexate is equally successful to salpingostomy in terms of requirement for further treatment. ${ }^{14}$

In the literature, successful treatment of cornual pregnancy with just a single dose of methotrexate has been reported. ${ }^{15,16}$ Medical treatment with a single methotrexate injection has been recommended. However, it is associated with significantly increased risk of failure, subsequent uterine rupture and emergency surgery. ${ }^{16} \mathrm{Kim}$ et al.17mentions a patient with $\beta$ hCG level of $1,02,970$ $\mathrm{mIU} / \mathrm{ml}$ who was successfully treated by systemic methotrexate (MTX). Another patient in the same study with a $\beta$ hCG level of $59,090 \mathrm{mIU} / \mathrm{ml}$ was treated by local MTX with a successful outcome.

Early diagnosis allows a varied choice of treatment options with high possibility of preserving fertility. ${ }^{3}$ In a haemodynamically stable patient, conservative management by local methotrexate or potassium chloride or systemic methotrexate is well established. Late first trimester or early second trimester rupture leading to catastrophic haemorrhage is common in interstitial pregnancies. They are managed surgically by cornual resection or hysterectomy. ${ }^{3}$

\section{CONCLUSION}

Cornual ectopic pregnancy is an uncommon variant and is a diagnostic and therapeutic challenge to clinician. The choice of treatment is largely dictated by clinical situation. Due to advanced gestation at the time of diagnosis, increased vascularity and anatomical difficulties cornual resection or hysterectomy was traditional approach. But keeping in view the present case, conservative approach is successful. Advanced cornual ectopic pregnancy could be managed successfully with hybrid MTX therapy to preserve fertility of the patient.

This particular case was neither meeting the conventional criteria for a medical management nor posed an emergent situation to operate. This case is a solitary one in literature, with such towering levels of $\beta$ hCG $(1,41,480 \mathrm{mIU} / \mathrm{ml})$, to be managed conservatively with MTX, resulting in a successful outcome. We could face the challenge sitting at a tertiary care centre with operational readiness round the clock.

\section{Funding: No funding sources Conflict of interest: None declared Ethical approval: Not required}

\section{REFERENCES}

1. Lin EP, Bhatt S, Dogra VS. Diagnostic clues to ectopic pregnancy. Radiographics. 2008;28(6):166171. 
2. Intapibool S. Unruptured left cornual pregnancy: case report. J Med Assoc Thai. 2005;88(8):1137-9.

3. Shendy M, Atalla R. Modern Management of Cornual Ectopic Pregnancy, Ectopic Pregnancy - Modern Diagnosis and Management. Michael Kamrava. 2011.

4. Royal College of Obstetricians and Gynaecologists. The Management of Tubal Pregnancy. Green Top Guideline. 2004;21.

5. Dey M, Lele PR, Tiwari S. Diverse Management of Cornual Ectopic Pregnancy. Int $\mathrm{J}$ Med Pharm. 2016;6(2):1-5.

6. Lele P, Tangri MK, Patil D, Sharma R. Recurrent Interstitial pregnancy: a new approach in diagnosis with MRI and management with systemic methotrexate along with intra foetal cardiac $10 \%$ potassium chloride; Int J Reprod Contracept Obstet Gynecol. 2016;5(2):539-41.

7. Timor-Tritsch IE, Monteagudo A, Matera C, Veit CR. Sonographic evolution of cornual pregnancies treated without surgery. Obstet Gynecol. 1992;79:1044-9.

8. Api M, Api O. Laparoscopic cornuotomy in the management of an advanced interstitial ectopic pregnancy: a case report. Gynecol Endocrinol. 2010;26(3):208-12.

9. MacRae R, Olowu O, Rizzuto MI, Odejinmi F. Diagnosis and laparoscopic management of 11 consecutive cases of cornual ectopic pregnancy. Arch Gynecol Obstet. 2009;280(1):59-64.

10. Tinelli A, Malvasi A, Pellegrino M, Pontrelli G, Martulli B, Tsin DA. Laparoscopical management of cornual pregnancies: a report of three cases. Eur J Obstet Gynecol Reprod Biol. 2010;151(2):199-202.
11. Surekha SM, Chamaraja T, Singh N, Singh LB, Neeraja TS. A ruputured lef cornual pregnancy: A case report. J Clin Diagn Res. 2013;7(7):1455-6.

12. Elson CJ, Salim R, Potdar N, Chetty M, Ross JA, Kirk EJ. Diagnosis and management of ectopic pregnancy. Int J Obstet Gynaecol. 2016;123(13):15-55.

13. Ackerman TE, Levi CS, Dashefsky SM, Holt SC, Lindsay DJ. Interstitial line: Sonographic finding in interstitial (cornual) ectopic pregnancy. Radiology. 1993;189(1):83-7.

14. Cassik P, Ofili-Yebovi D, Yazbek J, Lee C, Elson J, Jurkovic D. Factors influencing the success of conservative treatment of interstitial pregnancy. Ultrasound Obstet Gynecol. 2005;26(3):279-82.

15. Dilbaz S, Demir B, Dilbaz B. Treating cornual pregnancy with a single methotrexate injection-a case report of 3 cases. J Reprod Med Obstet Gynecol. 2005;50(2):141-4.

16. Gherman RB, Stitely M, Larrimore C. Low dose methotrexate treatment for interstitial pregnancy: a case report. J Reprod Med Obstet Gynecol. 2000;45(2):142-4.

17. Kim MJ, Cha JH, Bae HS, Kim MK, Yun BS, Kim YS, et al. Therapeutic outcomes of methotrexate injection in unruptured interstitial pregnancy: Obstet Gynecol Sci. 2017;60(6):571-8.

Cite this article as: Bajpai S, Lele P. A case of hybrid medical management of advanced cornual ectopic pregnancy. Int J Reprod Contracept Obstet Gynecol 2020;9:5179-82. 